Japan. J. Trop. Med., Vol. 10, 1, p. 26-28, 1969

\title{
A BRIEF REPORT ON THE SITUATION OF PREVALENCE MEDICAL PROBLEMS IN LAOS
}

\author{
OUNHEUAN PATHAMMAVONG \\ National Public Health Laboratory, Ministry of Health. Vietiane
}

\section{Some Preliminary Informations}

Laos is a tropical country, in the exact meaning on the word. The territory, in its most important part, is covered by huge forests. Its topography is generally mountaineus, but extensive plains suitable for large scale agriculture are found along the Mekong, from Vientiane to the extreme South of the country.

The rainfall pattern is characterized by a rainy season (from June to September) and a dry period during the rest of the year. The average temperature is about $30 \mathrm{C}$.

Fleeds constitute a permanent threat along the MeKong valley. The high rainfall between May and September also causes widespread fleeding, due to poor drainage. This is a cause for a pronounced increase in gastre-entric diseases, and favours fluke-infections.

The population of Laos is estimated at approximately 2,600,000. Its distribution is characterized by predominantly rural settlements (about $90 \%$ ) living in some 12,000 small villages. There are only five cities with populations of 10,000 and ever.

From the physical point of view, the country may be divided into two great regions : the lowlands along the Mekong, and, in the rest of the country, mountains covered by huge forests, without any means of communication. Consequently, two different types of pathology may be recognized in our country: the pathology of the lowlands, with a prevalence of malaria, helminthiasis and gastroenteric diseases, and the pathology of the mountain populations living in very poor hygienic conditions, underfed, and suffereing from pulmenary diseases. Some parasitic diseases are particular to that group, e.g. paragonimiasis. Malaria is slo prevalent in that part of the country. Following a WHO entomological survey, Anopheles minimus and Anopheles balabacensis have been named as the principal vectors.

Malaria: With exception of the town of Vientiane, it may be said that the disease is general in the whole territory. Malaria forms approximately a quarter of the dispensary work everywhere. During surveys in rural areas, it is usual to find the spleen enlarged in 80 to $90 \%$ of the children, and in $70 \%$ of adults. Malaria is responsible for most of the high infant mortality and morbidity. A control campaign was begun in 1957, American aid, but was interrupted due to the military and political conditions prevailing in the country.

In 1967, 4, 220 blood examinations were performed at the Central Laboratory in Vientiane. 269 were positive for $\mathrm{Pl}$. falciparum, and 328 for $\mathrm{Pl}$. vivax. Consequently, approximately $7 \%$ of the smears are positive. The Malaria Control Servise performed 15,862 examinations, and found 3,375 smears "positive" (exact nature of the parasite, undetermined). 
Water-related Diseases and Diseases Due to Poor Sanitation

Intestinal diseases form an important part of the pathology due to worms, Shigella, Salmonella and pathogenic Colibacilli. Tapeworms, mainly Taenia saginata, are commonly found, and Opisthorchis vivirrini is extremely widespread in the Mekong Valley. Evidence about the existence of schistosomiasis due to Schistosoma japonicum in the Southern part of the country was obtained recently- Stool examinations were performed on 547 inhabitants, and 8.59 were found positive by the direct smear method. No ova were found in the stools of mice and domestic animals living in the area. The common vector, the Oncomelania snail, was not found and it is expected that a WHO team will conduct a further survey during 1969 to identify the vector. In the meantime, it has been reported that Schistosoma japonicum infection has been detected along the Mekong further south, in Kratie, Cambodia. Paragonimiasis is occasionnally found in Vientiane among refugees from the mountains, or among soldiers returning from operations in the mountain areas. It is beliewed that foci of undetermined importance must exist in those regions, and further investigations would be necessary.

\section{Other Infection Diseases}

No cases of Cholera or Plague have been reported for many years, and the situation is the same with regard to smallpox. Yaws was common twenty years ago, but was successfully eradicated through a WHO eradication programme in the southern part of the country. Tuberculosis is a growing concern in our country, and is encountered as often in the growing urban population as in the poor and underfed mountain people. Considerable help is given by the U. N., with Consultantships and supply of drugs.

Leprosy: Approximately 2,000 cases are currently under treatment, the general

\begin{tabular}{lrc}
\hline No. of stool examinations performed & For whole Laos & $\begin{array}{c}\text { Vientiane } \\
\text { Laboratory }\end{array}$ \\
\hline Ankylostoma & 950 & 305 \\
Ascaris & 1464 & 514 \\
Taeniasis & 34 & 14 \\
Trichuris trichiura & 712 & 292 \\
Clonorchis or opistherchis & 621 & 221 \\
Trichomonas & 177 & 77 \\
Amoebiasis & 8 & 8 \\
Strongyleides stercoralis & 135 & 58 \\
Enterobius vermicularis & 5 & 5 \\
\hline
\end{tabular}

Here are the data eoncerning sputum examination:

\begin{tabular}{lrc}
\hline No. sputum examinations & $\begin{array}{c}\text { For whole Laos } \\
2799\end{array}$ & $\begin{array}{c}\text { Vientiane } \\
\text { Laboratory 1539 }\end{array}$ \\
\hline Positive for Mycob. Tuberculosis & 389 & 137 \\
Positive for Paragonimus & 14 & 14 \\
\hline
\end{tabular}


attitude of our Government being in favour of segregation. It is estimated that approximately 6,000 cases must exist in the country, which represents 2,3 for 1,000 inhabitants.

This brief survey of the must important medical problems of Laos is of course far from exhaustive. A huge effort remains to be made with regard to the improvement of public health, the establishment of correct statistics and the training of competent health personnel.

However, the state of war prevailing in the country for many years remains a serious obstacle for any valuable progress.

We hope that, with the fraternal help of the neighbouring countries, and after the establishment of a lasting peace, Laos will find its place among the members of a prosperous South-East Asia.

With regard to the importance of parasitic infestations in Laos, here are some statistics of stool examinations performed in 1967. 